\title{
Expression of genes encoding IGF1, IGF2, and IGFBPs in blood of obese adolescents with insulin resistance
}

\author{
Dmytro O. Minchenko ${ }^{1,2}$, Dariia O. Tsymbal ${ }^{1}$, Vadim V. Davy dov ${ }^{3}$, Oleksandr H. Minchenko ${ }^{1}$ \\ ${ }^{1}$ Department of Molecular Biology, Palladin Institute of Biochemistry, The National Academy of Sciences of Ukraine, \\ Kyiv, Ukraine; ${ }^{2}$ Departments of Pediatrics, Bohomolets National Medical University, Kyiv, Ukraine; ${ }^{3} S I$ "Institute of \\ Children and Adolescent Health Care, National Academy of Medical Science of Ukraine", Kharkiv, Ukraine \\ E-mail:ominchenko@yahoo.com
}

Objective. The development of obesity and its metabolic complications is associated with dysregulation of various intrinsic mechanisms, which control basic metabolic processes via changes in the expression of numerous regulatory genes. The main goal of this work was to study the association between the expression of insulin-like growth factors (IGF1 and IGF2) and IGF-binding proteins and insulin resistance in obese adolescents for evaluation of possible contribution of these genes in development of insulin resistance.

Methods. The expression of IGF1, IGF2, and IGFBPs mRNA was measured in blood of obese adolescents with normal insulin sensitivity and insulin resistance in comparison with the normal (control) individuals.

Results. In the blood of obese adolescents with normal insulin sensitivity the expression of IGFBP4, IGFBP5 and HTRA1 genes was down-regulated, but IGFBP2 and IGFBP7 genes up-regulated as compared to control (normal) group. At the same time, no significant changes in IGF1 and IGF2 gene expressions in this group of obese adolescents were found. Insulin resistance in obese adolescents led to up-regulation of IGF2, IGFBP2, and IGFBP7 gene expressions as well as to down-regulation of the expression of IGF1, IGFBP5 and HTRA1 genes in the blood in comparison with the obese patients, which have normal insulin sensitivity. Furthermore, the level of IGFBP4 gene expression was similar in both groups of obese adolescents.

Conclusions. Results of this investigation provide evidence that insulin resistance in obese adolescents is associated with gene specific changes in the expression of IGF1, IGF2, IGFBP2, IGFBP5, $I G F B P 7$, and HTRA1 genes and these changes possibly contribute to the development of glucose intolerance and insulin resistance.

Key words: mRNA expression, IGFs, IGFBPs, HTRA1, blood, obesity, insulin resistance

Childhood obesity is a serious and urgent public health problem because the number of children with severe obesity is significantly increased (Bass and Eneli 2015). Furthermore, children with severe obesity are at greater risk for adult obesity, early atherosclerosis, hypertension, metabolic syndrome, type 2 diabetes, fatty liver disease, and premature death (Bass and Eneli 2015). The development of obesity as well as its metabolic complications is associated with dysregulation of numerous intrinsic mechanisms, which control most key metabolic processes, including cellular growth, glucose, and lipid metabolism as well as insulin sensitivity (Ruderman et al. 2013; Tam et al. 2017; Ghoshal et al. 2018; Mao and Zhang 2018). Moreover, obesity as well as metabolic syndrome results from interactions between genes and envi-

Corresponding author: Oleksandr H. Minchenko, Department of Molecular Biology, Palladin Institute of Biochemistry, The National Academy of Sciences of Ukraine, Kyiv, Ukraine; e-mail: ominchenko@yahoo.com. 
ronmental factors and is associated with changes in gene expressions of regulatory network in various organs and tissues, but preferentially in adipose tissue (Shimba et al. 2011; Wang and Kaufman 2012; Han and Kaufman 2016; Mao and Zhang 2018). Adipose tissue growth is in a center of the obesity and is tightly associated with the glucose and lipid metabolism as well as cell proliferation processes. It is controlled by different interconnected regulatory factors and enzymes (Ozcan et al. 2004; Lee and Ozcan 2014). At the same time, the blood reflects numerous changes in different organs and tissues in diseases including obesity (Ando et al. 2011). Special interest deserves the key regulatory enzymes and factors, which control glucose and lipid metabolism as well as cell growth (Ruderman et al. 2013; Hassler et al. 2015; Han and Kaufman 2016; Tiaden et al. 2016; Ghoshal et al. 2018).

Receptors of insulin-like growth factor (IGF) and insulin as well as related proteins play an important role in the regulation of numerous metabolic and proliferative processes and participate in endoplasmic reticulum stress, which is an important factor of tumor growth, insulin resistance, and obesity (Pollak 2012; Kuijjer et al. 2013; Yuzefovych et al. 2013; Han and Kaufman 2014; Lee and Ozcan 2014). Furthermore, there exists a cross talk between IGF and insulin receptor signaling pathways at the receptor level or downstream signaling level. This cross talk significantly changed the IGF/insulin receptor isoforms in a variety of cancers. Overexpression and formation of hybrid receptor isoforms between IGF1 receptor and insulin receptor, which are sensitive to the stimulation of all three IGF axis ligands, as well as hybrid receptors of IGF1 receptor and insulin receptor with other tyrosine kinases, potentiate the cellular transformation, tumorigenesis, and tumor vascularization (Kuijjer et al. 2013).

The insulin-like growth factor binding proteins (IGFBPs) bind and regulate the availability of both IGFs, prolong the half-life of the IGFs, and inhibit or stimulate the growth promoting effects of the IGFs through IGF/INS receptors. Now, they are understood to have many actions beyond their endocrine role in IGF transport (Foulstone et al. 2013; Liu et al. 2014; Maridas et al. 2017; Cai et al. 2018). Moreover, IGFBP2 not only modulates IGFs but also directly regulates PTEN and has a role in the maintaining of the estrogen receptor-alpha expression and plays an important role in the tumorigenesis promotion (Foulstone et al. 2013; Ahani et al. 2014; Huang et al. 2017; Li et al. 2017). Additionally, IGFBP2 is increased the expression of p-p65 and nuclear p65, while IGFBP2 knockdown reduced the NF- $\kappa$ B signaling pathway (Yuan et al. 2017). It is interesting to note that both IGFBP1 and IGFBP2 are linked to insulin resistance, obesity, the type 2 diabetes, and metabolic syndrome, because they are at the interface of growth and metabolism (Sabin et al. 2011; Gokulakrishnan et al. 2012; Kim and Lee 2015).

IGFBP4 preferentially binds to IGF2 and regulates growth and development of tissues and organs by negatively regulating IGF signaling. It has also IGF-independent effects including inhibition of angiogenesis and promotion of cancer cell migration (Praveen Kumar et al. 2014). This IGF binding protein is required for adipogenesis and influences the distribution of adipose depots (Maridas et al. 2017). The IGFBP5, which is often dysregulated in human cancers, plays a crucial role in the carcinogenesis and cancer development, preferentially acts as an important tumor suppressor, and the proliferation of IGFBP5-mutated cancer cells is selectively blocked by IGF1R inhibitors (Wang et al. 2015; Ding et al. 2016; Neuzillet et al. 2017).

The HTRA1/PRSS11 gene encoded serine protease with IGF-binding domain, which functioning as important modulators of many physiological processes, including cell signaling and apoptosis, regulates the availability of IGFs by cleaving IGFBPs and has a pivotal role in both cell proliferation and differentiation (D'Angelo et al. 2014; Zurawa-Janicka et al. 2017; Schillinger et al. 2018). Recently, it has been shown that lysyl oxidase regulates the epidermal growth factor receptor to facilitate its activation by EGF to drive tumor progression by suppressing TGF $\beta 1$ signaling through the secreted protease HTRAl (Tang et al. 2017). There are data indicating that HTRA1, as a negative regulator of mesenchymal stem cells adipogenesis, participates in the adipose tissue remodeling under pathological conditions (Tiaden et al. 2016).

Many different factors affecting the homeostasis have been shown to induce a complex of intracellular signaling events in the endoplasmic reticulum, which is known as the unfolded protein response/endoplasmic reticulum stress (Wang and Kaufman 2016; Minchenko et al. 2014; Lee and Ozcan 2014; Manie et al. 2014). It participates in the early cellular response to the accumulation of misfolded proteins in the lumen of the endoplasmic reticulum, which is a dynamic intracellular organelle with exquisite sensitivity to alterations in homeostasis, and provides stringent quality control systems to ensure that only correctly folded proteins transit to the Golgi apparatus and unfolded or misfolded proteins are retained and ultimately degraded (Ferris et al. 2014; Doultsinos et 
al. 2017). Activation of the endoplasmic reticulum stress sensors leads to the transcriptional reprogramming of the cells (Chevet et al. 2015). Moreover, inhibition of IRE1 mediated signaling pathway of endoplasmic reticulum stress affects the expression of proliferation-related and many other genes including insulin-like growth factor binding protein genes (Auf et al. 2013; Minchenko et al. 2015a,b; Minchenko et al. 2016). The endoplasmic reticulum stress is recognized as an important determinant of cancer, obesity and type 2 diabetes and contributes to the expression profile of many regulatory genes resulting in proliferation, apoptosis, and peripheral insulin resistance (Ozcan et al. 2004; Han and Kaufman 2014; Lee and Ozcan 2014; Manie et al. 2014; Chevet et al. 2015), although detailed molecular mechanisms cannot be ruled out.

It is possible that identification of real mechanisms of metabolic abnormalities in obesity as well as its complications at molecular and cellular levels helps to better understand why the obesity develops and why only a part of the obese individuals develops secondary metabolic disorders. However, a detailed molecular mechanism of the involvement of different genes of regulatory network in the development of obesity and its complications are not clear yet and remains to be determined.

The main goal of this study was to clarify the role of the expression of a subset of genes, encoding for important cell growth (IGFs) and IGFBPs, in blood of obese adolescents for evaluation of its possible significance for the development of obesity and insulin resistance.

\section{Materials and methods}

Patients' clinical characteristics. The 21 male adolescents participate in this study. They were divided into three equal groups (7 subjects in each group): one group of normal individuals as control and two groups of obese patients: with or without insulin resistance. All participants gave written informed consent and the studies were approved by the local research ethics committees of Institute of Children and Adolescent Health Care of the National Academy of Medical Science of Ukraine.

Clinical characteristics of the study participants are shown in Table 1. The normal (control) participants were individuals with mean age $14.2 \pm 0.584$ years and mean body mass index (BMI) $18.8 \pm 0.17 \mathrm{~kg} / \mathrm{m}^{2}$. The obese participants with normal insulin sensitivity as well as the patients with insulin resistance were individuals with mean age (13.8 \pm 0.265 and $14.5 \pm 0.297$ years, respectively) and mean BMI $\left(31.1 \pm 0.36\right.$ and $34.3 \pm 1.72 \mathrm{~kg} / \mathrm{m}^{2}$, correspondingly). Thus, BMI, which is a main criterion of obesity, in these last two groups of patients was significantly higher (+65 and $+82 \%$, respectively; $\mathrm{p}<0.01$ in both cases) as compared to control individuals (Table 1). Moreover, no significant changes were found in insulin resistance index (HOMA) in obese individuals as compared to control group, but in obese patients with impaired insulin sensitivity, versus control boys as well as obese subjects with normal insulin sensitivity the insulin resistance index is significantly increased (3.6- and 3.2-fold, respectively; $\mathrm{p}<0.001$ in both cases) (Table 1). Similar results were observed in the fasting insulin levels: no significant changes in obese individuals and strong increase in obese adolescents with insulin resistance (3.3.-fold, $\mathrm{p}<0.001$, as compared to control group and 3 -fold, $\mathrm{p}<0.001$, as compared to obese adolescents without insulin resistance) as compared to control group. At the same time, both obesity and obesity with insulin resistance did not change significantly the level of fasting glucose, since $2 \mathrm{~h}$ oral glucose tolerance test (OGTT) was significantly higher $(+29 \%$, respectively; $\mathrm{p}<0.05)$, but only in the group of obese adolescents with insulin resistance as compared to control individuals (Table 1).

Table 1

Characteristics of the study participants

\begin{tabular}{llll}
\hline Parameter & Control & Obesity & Obesity+IR \\
\hline Age at visit (years) & $14.2 \pm 0.584$ & $13.8 \pm 0.265$ & $14.5 \pm 0.297$ \\
Body mass index $(\mathrm{BMI})\left(\mathrm{kg} / \mathrm{m}^{2}\right)$ & $18.8 \pm 0.17$ & $31.1 \pm 0.36^{*}$ & $34.3 \pm 1.72^{*}$ \\
Insulin resistance index $(\mathrm{HOMA})$ & $2.38 \pm 0.128$ & $2.63 \pm 0.219$ & $8.51 \pm 0.99^{\star \wedge}$ \\
Fasting insulin $(\mathrm{IU} / \mathrm{ml})$ & $12.8 \pm 0.69$ & $14.3 \pm 0.95$ & $42.5 \pm 4.69^{* \wedge}$ \\
Fasting glucose $(\mathrm{mmol} / \mathrm{l})$ & $4.07 \pm 0.177$ & $4.3 \pm 0.183$ & $4.6 \pm 0.176$ \\
2h oral glucose tolerance test (OGTT) glucose $(\mathrm{mmol} / \mathrm{l})$ & $4.19 \pm 0.124$ & $4.74 \pm 0.215$ & $5.41 \pm 0.253^{*}$ \\
\hline
\end{tabular}

Data are presented as mean \pm SEM, $n=7$. ${ }^{\star} \mathrm{p}<0.05$ versus control group; $\wedge \mathrm{p}<0.05$ versus obese group. 
RNA isolation. Trisol reagent (Invitrogen, USA) was used for RNA extraction from blood of normal (control) and obese individuals with or without insulin resistance as described previously (Auf et al. 2013). The RNA pellets were washed with $75 \%$ ethanol and dissolved in nuclease-free water. For additional purification RNA samples were re-precipitated with 95\% ethanol and re-dissolved in nuclease-free water. RNA concentration as well as spectral characteristics was measured using NanoDrop Spectrophotometer ND1000 (PEQLAB, Biotechnologie GmbH).

Reverse transcription and quantitative real-time polymerase chain reaction analysis. Thermo Scientific Verso cDNA Synthesis Kit was used for reverse transcription. The expression level of IGF1, IGF2, IGFBP2, IGFBP4, IGFBP5, IGFBP7, and HTRA1 genes were measured in RNA samples from blood by realtime quantitative polymerase chain reaction of complementary DNA (cDNA). The "QuantStudio 5 RealTime PCR System" (Applied Biosystems), Absolute QPCR SYBRGreen Mix (Thermo Scientific, UK) and pair of primers specific for each studied gene (Sigma/ Aldrich, USA) was used for quantitative polymerase chain reaction (Table 2).

The expression of beta-actin mRNA was used as control of analyzed RNA quantity. The amplified DNA fragments were analyzed on a $2 \%$ agarose gel and that visualized by $5 \mathrm{x}$ Sight DNA Stain (EUROMEDEA). An analysis of quantitative PCR was performed using special computer program "Differential expression calculator". Statistical analyses were performed according to Student's $t$-test using OriginPro 7.5 software. All values are expressed as mean \pm SEM from seven independent experiments; $\mathrm{p}<0.05$ was considered as significant difference.

\section{Results}

We analyzed the expression of a subset of genes encoding IGF1, IGF2, IGFBP2, IGFBP4, IGFBP5, IGFBP7, and HTRA1, which are associated with cell proliferation, glucose and lipid metabolism, in blood cells of three groups: normal (control) adolescents, obese boys with normal insulin sensitivity, and obese individuals with insulin resistance using quantitative polymerase chain reaction. As shown in Figure 1, the expression level of IGF1 and IGF2 genes in the blood of obese adolescents with normal sensitivity to insulin did not change significantly (Figures 1 and 2). At the same time, the expression level of IGF1 gene is significantly decreased $(-30 \%$; $\mathrm{p}<0.05)$ in obese adolescents with insulin resistance as compared to control group (Figure 1). Moreover, the similar changes in the expression level of IGF1 gene were also observed in the blood of obese individuals with insulin resistance as compared to the group of obese adolescents without insulin resistance $(-32 \% ; \mathrm{p}<0.05)$. We have also shown that the development of insulin resistance in obese individuals leads to up-regulation of the expression level of IGF2 gene in the blood: $+12 \%(\mathrm{p}<0.05)$ as compared to control group and $+15 \%(\mathrm{p}<0.05)$ as compared to the group of obese individuals with normal sensitivity to insulin (Figure 2).

We also found that development of obesity with normal sensitivity to insulin leads to up-regulation

Table2

Characteristics of the primers used for quantitative real-time polymerase chain reaction

\begin{tabular}{|c|c|c|c|c|}
\hline $\begin{array}{l}\text { Gene } \\
\text { symbol }\end{array}$ & Gene name & Primer's sequence & $\begin{array}{c}\text { Nucleotide numbers } \\
\text { in sequence }\end{array}$ & $\begin{array}{c}\text { GenBank a } \\
\text { ccession number }\end{array}$ \\
\hline IGF1 & $\begin{array}{l}\text { Insulin-like growth factor } 1 \\
\text { (somatomedin C) }\end{array}$ & $\begin{array}{l}\text { F: 5'- catgtcctcctcgcatctct } \\
\text { R: 5'-ggtgcgcaatacatctccag }\end{array}$ & $\begin{array}{l}297-316 \\
551-532\end{array}$ & NM_000618 \\
\hline IGF2 & $\begin{array}{l}\text { insulin-like growth factor } 2 \\
\text { (somatomedin A) }\end{array}$ & $\begin{array}{l}\text { F: 5' - caatggggaagtcgatgctg } \\
\text { R: } 5 \text { - ggaaacagcactcctcaacg }\end{array}$ & $\begin{array}{l}763-782 \\
969-950\end{array}$ & NM_000612 \\
\hline IGFBP2 & $\begin{array}{l}\text { insulin-like growth factor binding } \\
\text { protein } 2\end{array}$ & $\begin{array}{l}\text { F: 5'- cctcaagtcgggtatgaaggag } \\
\text { R: 5'- caacaggaactggaccaggt }\end{array}$ & $\begin{array}{l}669-688 \\
830-811\end{array}$ & NM_001901 \\
\hline IGFBP4 & $\begin{array}{l}\text { insulin-like growth factor binding } \\
\text { protein } 4\end{array}$ & $\begin{array}{l}\text { F: 5'- caccccaacaacagcttcag } \\
\text { R: 5'- agttggggatggggatgatg }\end{array}$ & $\begin{array}{l}679-698 \\
922-903\end{array}$ & NM_001552 \\
\hline IGFBP5 & $\begin{array}{l}\text { insulin-like growth factor binding } \\
\text { protein } 5\end{array}$ & $\begin{array}{l}\text { F: 5'- agtgaagaaggaccgcagaa } \\
\text { R: 5'- gcagcttcatcccgtacttg }\end{array}$ & $\begin{array}{l}1227-1246 \\
1528-1509\end{array}$ & NM_000599 \\
\hline IGFBP7 & $\begin{array}{l}\text { insulin-like growth factor binding } \\
\text { protein } 7 \text { (angiomodulin) }\end{array}$ & $\begin{array}{l}\text { F: } 5 \text { '- agctgtgaggtcatcggaat } \\
\text { R: } 5 \text { '- tatagctcggcaccttcacc }\end{array}$ & $\begin{array}{l}572-591 \\
882-863\end{array}$ & NM_001553 \\
\hline HTRA1 & $\begin{array}{l}\text { high temperature requirement factor } \\
\text { A1 (HtrA serine peptidase } 1)\end{array}$ & $\begin{array}{l}\text { F: 5' - tggaatctcctttgcaatcc } \\
\text { R: 5'- acgctcctgagatcacgtct }\end{array}$ & $\begin{array}{l}1175-1194 \\
1365-1346\end{array}$ & NM_002775 \\
\hline ACTB & beta-actin & $\begin{array}{l}\text { F: 5'- ggacttcgagcaagagatgg } \\
\text { R: 5'- agcactgtgttggcgtacag }\end{array}$ & $\begin{array}{l}747-766 \\
980-961\end{array}$ & NM_001101 \\
\hline
\end{tabular}




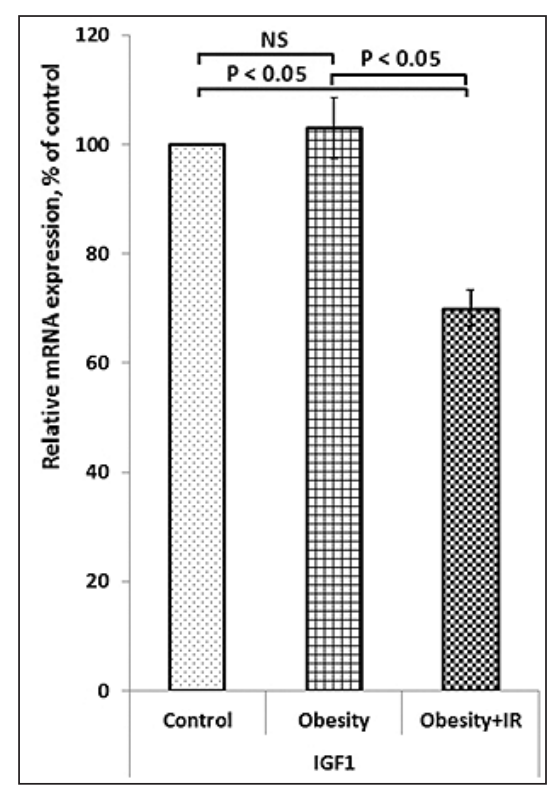

Figure 1. Expression of insulin-like growth factor 1 (IGF1) mRNA in blood of obese individuals with normal insulin sensitivity (Obesity) and obese patients with insulin resistance (Obesity+IR) as well as in normal adolescents (Control). The values of this mRNA expression were normalized to the expression of beta-actin mRNA, expressed as mean \pm SEM and represented as a percent of control $(100 \%) ; \mathrm{n}=7$.

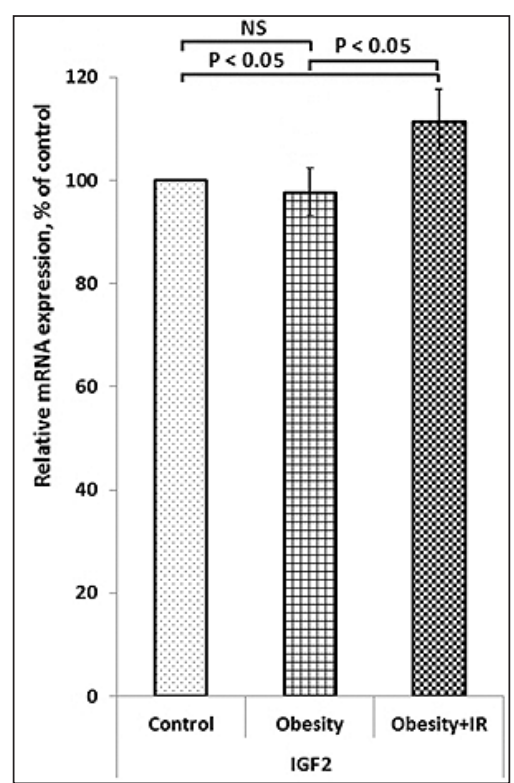

Figure 2. Expression of insulin-like growth factor 2 (IGF2) mRNA in blood of obese individuals with normal insulin sensitivity (Obesity) and obese patients with insulin resistance (Obesity+IR) as well as in normal adolescents (Control). The values of this mRNA expression were normalized to the expression of betaactin mRNA, expressed as mean \pm SEM and represented as a percent of control (100\%); $\mathrm{n}=7$.

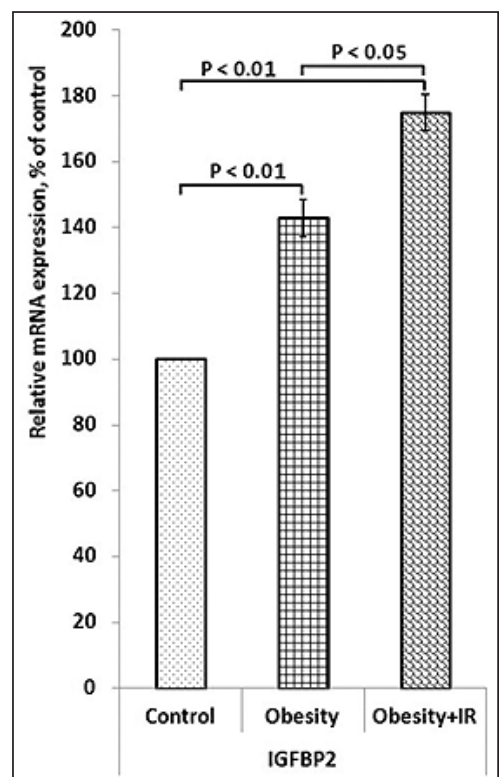

Figure 3. Expression of insulinlike growth factor binding protein 2 (IGFBP2) mRNA in blood of obese individuals with normal insulin sensitivity (Obesity) and obese patients with insulin resistance (Obesity+IR) as well as in normal adolescents (Control). The values of this mRNA expression were normalized to the expression of beta-actin mRNA, expressed as mean \pm SEM and represented as a percent of control $(100 \%) ; n=7$. of the expression of IGF binding protein 2 in the blood $(+43 \%$; $p<0.01)$ as compared to control group of adolescents (Figure 3). More strong changes in this gene expression were observed in obese individuals with impaired sensitivity to insulin: $+75 \%(\mathrm{p}<0.01)$ as compared to control group and $+22 \%(\mathrm{p}<0.05)$ as compared to the group of obese individuals with normal sensitivity to insulin (Figure 3).

As shown in Figure 4, the expression of IGFBP4, which is a non-classical IGFBP molecule with an important IGF-independent effect including inhibition of angiogenesis and control of adipogenesis as well as the distribution of adipose depots, is down-regulated in the blood of both group of obese adolescents (with normal sensitivity to insulin and insulin resistance): -31 and $-35 \%$, respectively; $\mathrm{p}<0.05$ in both cases. Thus, the development of insulin resistance in obese adolescents does not change significantly the expression level of this IGF binding protein.

The expression level of IGFBP5 mRNA is also decreased in obese adolescents with normal sensitivity to insulin as compared to control cells $(-22 \%$, Figure 5). Therefore, the development of insulin resistance in obese individuals led to more prominent changes in IGFBP5 mRNA expression: $-47 \%$ $(\mathrm{p}<0.01)$ as compared to control group and $-24 \%$ $(\mathrm{p}<0.05)$ as compared to the group of obese adolescents with normal sensitivity to insulin (Figure 5). It is possible that changes in the expression of IGFBP5, which preferentially acts as an important tumor suppressor, can contribute to the development of obesity and insulin resistance as well as other obesity complications.

Next, we investigated the expression level of IGFBP7 mRNA in the blood of obese adolescents with normal sensitivity to insulin and insulin resistance. As shown in Figure 6, the expression level of IGFBP7 significantly increases in the group of obese individuals with normal sensitivity to insulin $(+76 \%$; $\mathrm{p}<0.01)$ as compared to control group of adolescents (Figure 6). More strong changes in this gene expression were observed in obese individuals with impaired sensitivity to insulin: $+148 \%(\mathrm{p}<0.001)$ as compared to control group and $+41 \%(\mathrm{p}<0.01)$ as compared to the group of obese individuals with normal sensitivity to insulin (Figure 6). 


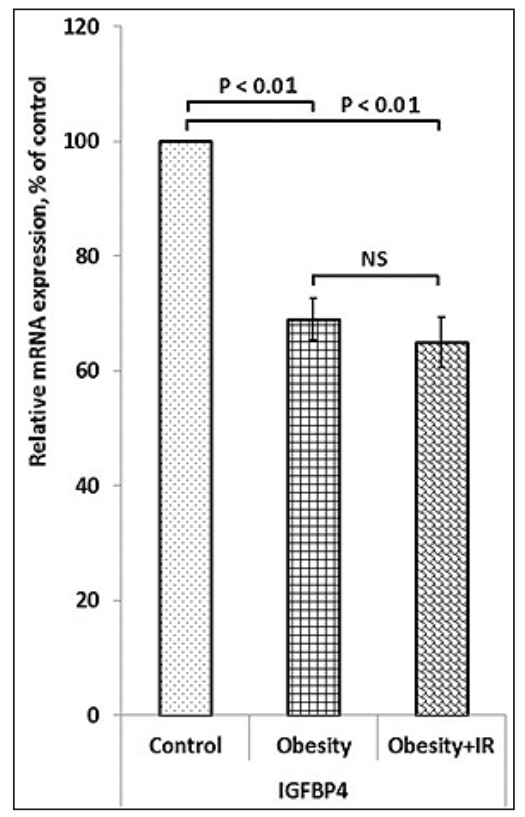

Figure 4. Expression of insulinlike growth factor binding protein 4 (IGFBP4) mRNA in blood of obese individuals with normal insulin sensitivity (Obesity) and obese patients with insulin resistance (Obesity+IR) as well as in normal adolescents (Control). The values of this mRNA expression were normalized to the expression of betaactin mRNA, expressed as mean \pm SEM and represented as a percent of control $(100 \%) ; \mathrm{n}=7$.

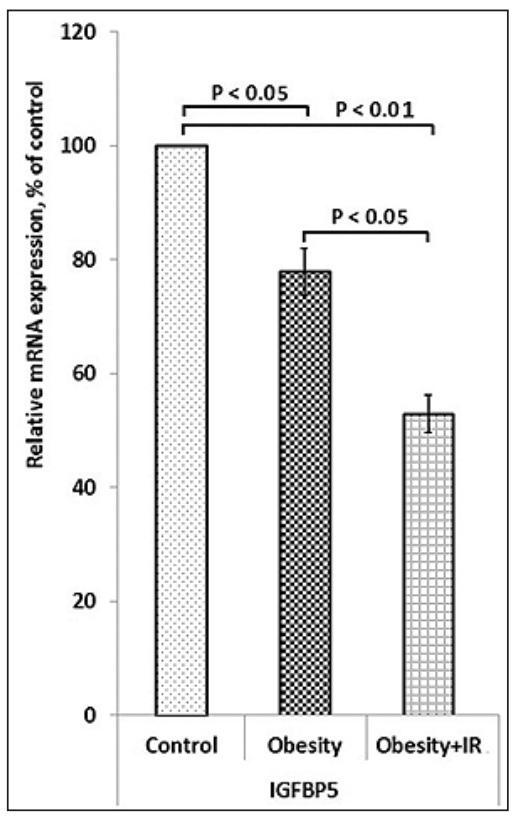

Figure 5. Expression of insulinlike growth factor binding protein 5 (IGFBP5) mRNA in blood of obese individuals with normal insulin sensitivity (Obesity) and obese patients with insulin resistance (Obesity+IR) as well as in normal adolescents (Control). The values of this mRNA expression were normalized to the expression of betaactin mRNA, expressed as mean \pm SEM and represented as a percent of control $(100 \%) ; \mathrm{n}=7$.

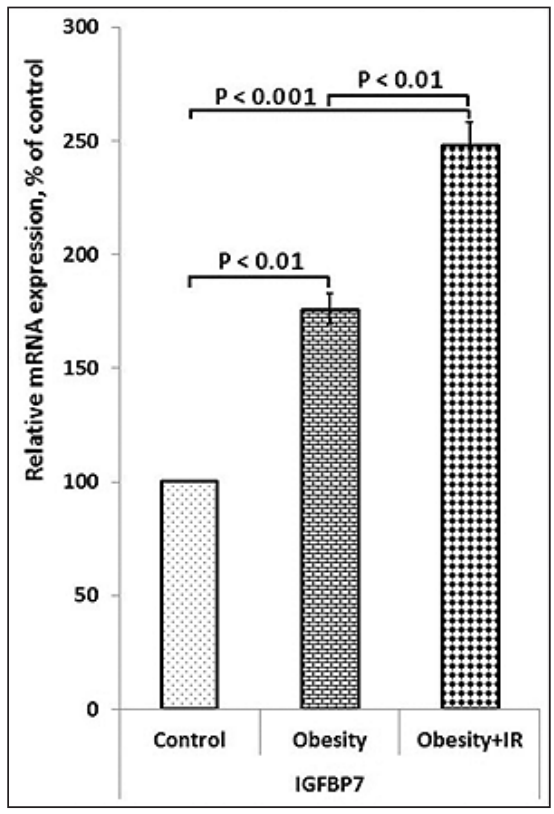

Figure 6. Expression of insulin-like growth factor binding protein 7 (IGFBP7) mRNA in blood of obese individuals with normal insulin sensitivity (Obesity) and obese patients with insulin resistance (Obesity+IR) as well as in normal adolescents (Control). The values of this mRNA expression were normalized to the expression of beta-actin mRNA, expressed as mean \pm SEM and represented as a percent of control (100\%); $n=7$.
We have also studied the expression level of hightemperature requirement $A$ serine peptidase 1 , which is a stress responsible enzyme and also known as a serine protease with IGF-binding domain PRSS11. As shown in Figure 7, this mRNA expression is decreased in the blood of obese adolescents with normal sensitivity to insulin $(-14 \%$; $\mathrm{p}<0.05)$. Therefore, development of insulin resistance leads to more prominent changes in HTRA1 mRNA expression: $-30 \%(\mathrm{p}<0.05)$ as compared to control group and $-19 \%(\mathrm{p}<0.05)$ as compared to the group of obese adolescents with normal sensitivity to insulin (Figure 7).

\section{Discussion}

Results of this investigation clearly demonstrate that obesity alters the expression level of all studied IGF binding protein genes in gene-specific manner in the blood and that these changes preferentially are insulin sensitive (Figure 8). Thus, the expression level of IGFBP2 and IGFBP7 genes is increased, but - IGFBP4,
IGFBP5, and HTRA1 genes is decreased in obese individuals with normal sensitivity to insulin. Similar, but more prominent changes were shown for all these genes, except IGFBP4, in obese adolescents with insulin resistance. At the same time, the expression level of IGF1 and IGF2 did not change significantly in obese individuals with normal sensitivity to insulin, but biological activity of both these growth factors possibly is affected in obesity with normal sensitivity to insulin because significant changes were observed in different IGF binding proteins, which bind and regulate the availability of both IGFs, their half-life and inhibit or stimulate the growth promoting effects of the IGFs through IGF/INS receptors (Baxter 2014). However, development of insulin resistance affects the expression of both IGF genes: decreases IGF1 and increases IGF2 (Figure 8).

The development of obesity as well as its metabolic complications is associated with dysregulation of numerous intrinsic mechanisms, which control most key metabolic processes, including cellular growth, 


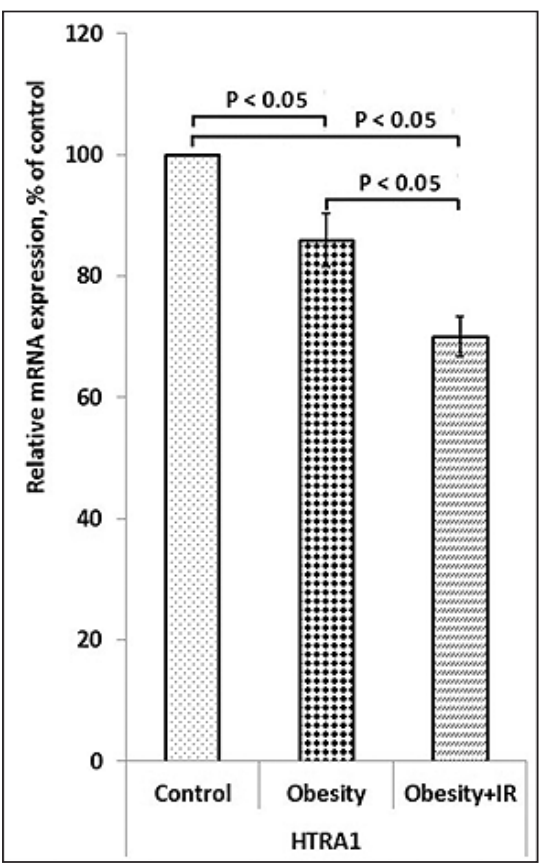

Figure 7. Expression of high temperature requirement factor A1 (HTRA1) mRNA in blood of obese individuals with normal insulin sensitivity (Obesity) and obese patients with insulin resistance (Obesity+IR) as well as in normal adolescents (Control). The values of this mRNA expression were normalized to the expression of beta-actin mRNA, expressed as mean \pm SEM and represented as a percent of control (100\%); $\mathrm{n}=7$.
2014; Lee and Ozcan 2014; Sunderic et al. 2014). Furthermore, there exists a cross talk between IGFs and insulin receptor signaling pathways at the receptor level or downstream signaling level (Kuijjer et al. 2013). It is interesting to note that insulin/IGFs can regulate a long non-coding RNA CRNDE, which control genes involved in central metabolism (Ellis et al. 2014). Recently, Sun et al. (2018) demonstrate that both INSR and IGF1R are directly targeted by C-myc and exert similar effects to promote the tumorigenesis and metastasis of TSCC through the NF-kappa B pathway. Moreover, insulin-like growth factor 2 expression in prostate cancer is regulated by promoter-specific methylation (Kuffer et al. 2018). Disruption of this gene alters hepatic lipid homeostasis and gene expression in the newborn mouse (Lopez et al. 2018).

The insulin-like growth factor binding proteins bind and regulate the availability of both IGFs, prolong the half-life of the IGFs, and inhibit or stimulate the growth promoting effects of the IGFs through IGF/INS receptors. They are now understood to have many actions beyond their endocrine role in IGF transport (Foulstone et al. 2013; Liu et al. 2014; Maridas et al. 2017; Cai et al. 2018). There is now substantial evidence linking IGFBP-2 with nutritional status and insulin sensitivity (Sabin et al. 2011). IGFBPs are also functioning in the pericellular and intracellular compartments to regulate cell growth and survival (Holmes et al. 2012). Because they interact with many proteins, IGF1 and IGF2, in addition to their canonical ligands, also play an intranuclear role in the regulation of transcription (Baxter 2014; Praveen Kumar et al. 2014).

Taking into account the importance of IGFBPs function, we suggest that obesity-mediated down-regulation of IGFBP4 and IGFBP5 as well as up-regulation of IGFBP2 and IGFBP7 gene expressions glucose, and lipid metabolism as well as insulin sensitivity (Ruderman et al. 2013; Martin et al. 2015; Tam et al. 2017; Ghoshal et al. 2018; Mao and Zhang 2018). It is possible that changes in IGFs and IGFBPs, which we observed in childhood obesity with and without insulin resistance, can contribute to these numerous intrinsic mechanisms of glucose and lipid metabolism dysregulation as well as cellular growth, because insulin-like growth factors and related proteins play an important role in the regulation of numerous metabolic and proliferative processes and participate in endoplasmic reticulum stress, an important factor of insulin resistance and obesity (Pollak 2012; Kuijjer et al. 2013; Yuzefovych et al. 2013; Han and Kaufman

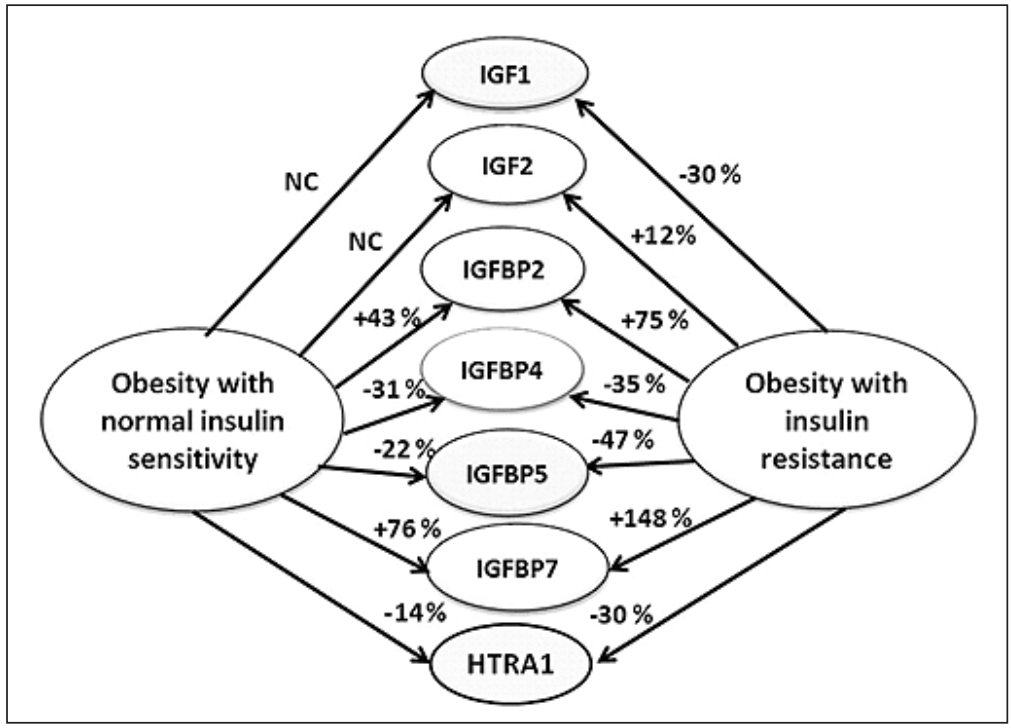

Figure 8. Schematic demonstration of IGF1, IGF2, IGFBP2, IGFBP4, IGFBP5, $I G F B P 7$, and HTRA1 genes expression profile the blood of obese adolescences with normal insulin sensitivity and insulin resistance as compared to control group. NC - no significant changes. 
may contribute to the dysregulation of glucose and lipid metabolism. Moreover, our results clearly indicate that obesity is a risk factor for tumorigenesis, because IGFBP2 not only modulates IGFs but also directly regulates PTEN, has a role in the maintaining of the estrogen receptor-alpha expression and plays an important role in promoting tumorigenesis, through estrogen and estrogen receptor-alpha signaling pathway (Foulstone et al. 2013; Huang et al. 2017; Li et al. 2017). Recently, it has been shown that exogenous IGFBP2 promotes proliferation and invasion in glioma cells via the integrin $\beta 1$-ERK pathway and that this IGFBP with MDA9/syntenin promotes angiogenesis in human melanoma (Han et al. 2014). Ord et al. (2015) have shown that cell viability during glucose deprivation is enhances by TRIB3 (pseudokinase Tribbles homolog 3) through upregulation of IGFBP2, which is recognized as a novel nutrient deficiency survival factor. Furthermore, IGFBP2 is a direct and functional downstream target of microRNA-592, which is involved in the microRNA-592-mediated tumor-suppressive effects in glioma cells (Peng et al. 2017). It is interesting to note that both IGFBP1 and IGFBP2 are linked to insulin resistance, obesity, and the type 2 diabetes mellitus, and metabolic syndrome, because they are at the interface of growth and metabolism (Sabin et al. 2011; Gokulakrishnan et al. 2012; Kim and Lee 2015). High level of IGFPB7 expression in obese individuals can also play a role in promoting tumorigenesis, because there is data that the low levels of IGFPB7 in high-grade serous ovarian carcinoma relative to normal tissues, and association with survival are consistent with a purported role in tumor suppressor pathways (Liu et al. 2014; Gambaro et al. 2015).

In this study we showed that obesity down-regulates the expression of both IGFBP4 and IGFBP5, which was preferentially shown with tumor suppressor properties by negatively regulating IGF signaling as well as through IGF-independent effects including inhibition of angiogenesis and promotion of cancer cell migration (Praveen Kumar et al. 2014). Our results are consistent with the data of Hermani et al. (2013) that IGFBP4 modulates ligand-dependent estrogen receptor-alpha activation in breast cancer cells in an IGF-independent manner through activation of the Akt/PKB signaling pathway as well as to data Contois et al. (2015), that inhibition of tumor-associated $\alpha v \beta 3$ integrin regulates the angiogenic switch by enhancing the expression of IGFBP4, as important negative regulator of IGF-1 signaling, leading to reduced melanoma growth and angiogenesis in vivo. It is useful to note that in the upstream region of IGFBP4 gene is located lncRNA (lnc-IGFBP4-1), which is significantly up-regulated in lung cancer tissues and plays a positive role in cell proliferation and metastasis through possible mechanism of reprogramming tumor cell energy metabolism (Yang et al. 2017). The IGFBP5, which is often dysregulated in human cancers, plays a crucial role in the carcinogenesis and cancer development, preferentially acts as an important tumor suppressor and the proliferation of IGFBP5-mutated cancer cells is selectively blocked by IGF1R inhibitors (Wang et al. 2015; Ding et al. 2016; Neuzillet et al. 2017). Furthermore, overexpression of IGFBP5 suppresses epithelial-mesenchymal transition and decreases the expression of E-cadherin, exerts its inhibitory activities by reducing the phosphorylation of IGF1R, ERK1/2, and p38-MAPK kinases and abating the expression of HIFla and its target genes, VEGF and MMP9 (Wang et al. 2015; Hwang et al. 2016). These data completely agree with our results, which demonstrated possible mechanism connecting obesity with tumorigenesis as well as with data of Tsuchihara et al. (2008).

We also showed that obesity down-regulates the expression of HTRA1 gene encoded serine protease with IGF-binding domain, which functions as important modulators of many physiological processes, including cell signaling and apoptosis, regulates the availability of IGFs by cleaving IGFBPs and has a pivotal role in both cell proliferation and differentiation (D'Angelo et al. 2014; Zurawa-Janicka et al. 2017; Schillinger et al. 2018). Our results concerning the obesity related changes in HTRA1 expression agree with data of Tiaden et al. (2016) that this enzyme, as a negative regulator of mesenchymal stem cells adipogenesis, participates in the adipose tissue remodeling under pathological conditions. It is also useful to note that highly conserved serine protease HTRA1 also degrades amyloid fibrils in an ATP-independent manner (Poepsel et al. 2015). It solubilizes protein fibrils and disintegrates the fibrillary core structure, allowing productive interaction of aggregated polypeptides with the active site for rapid degradation. It has also been shown that brain injury induces HTRA1 expression in reactive astrocytes, and loss of HTRA1 leads to an impairment in wound closure accompanied by increased proliferation of endothelial and immune cells (Chen et al. 2018). It is possible that obesity and insulin resistance related down-regulation of HTRA1 participates in the development of some obesity complications.

Previously, it has been shown that IGF1, IGF2, and all studied IGFBPs are responsible from endoplasmic reticulum stress, which is recognized as an important 
determinant of obesity and type 2 diabetes and contributes to the expression profile of many regulatory genes resulting in proliferation, apoptosis, and peripheral insulin resistance (Han and Kaufman 2014; Lee and Ozcan 2014; Manie et al. 2014; Chevet et al. 2015; Minchenko et al. 2015a, 2016). Therefore, it is possible that most obesity and insulin related changes in the expression of IGFs and IGFBPs genes are mediated through endoplasmic reticulum stress, although detailed molecular mechanisms cannot be ruled out.
It is possible that identification of real mechanisms of metabolic abnormalities in obesity as well as its complications at molecular and cellular levels leads to a better understanding why obesity develops and why only a part of the obese individuals develops secondary metabolic disorders. However, a detailed molecular mechanism of the involvement of different genes of regulatory network in the development of obesity and its complications are not clear yet and remains to be determined.

\section{References}

Ahani N, Karimi Arzenani M, Shirkoohi R, Rokouei M, Alipour Eskandani M, Nikravesh A. Expression of insulinlike growth factor binding protein-2 (IGFBP-2) gene in negative and positive human cytomegalovirus glioblastoma multiforme tissues. Med Oncol 31, 812, 2014.

Ando H, Kumazaki M, Motosugi Y, Ushijima K, Maekawa T, Ishikawa E, Fujimura A. Impairment of peripheral circadian clocks precedes metabolic abnormalities in ob/ob mice. Endocrinology 152, 1347-1354, 2011.

Auf G, Jabouille A, Delugin M, Guerit S, Pineau R, North S, Platonova N, Maitre M, Favereaux A, Vajkoczy P, Seno M, Bikfalvi A, Minchenko D, Minchenko O, Moenner M. High epiregulin expression in human U87 glioma cells relies on IRE1 alpha and promotes autocrine growth through EGF receptor. BMC Cancer 13, 597, 2013.

Bass R, Eneli I. Severe childhood obesity: an under-recognised and growing health problem. Postgrad Med J 91, 639-645, 2015.

Baxter RC. IGF binding proteins in cancer: mechanistic and clinical insights. Nat Rev Cancer 14, 329-341, 2014.

Cai X, Wang L, Wang X, Hou F. Silence of IGFBP7 suppresses apoptosis and epithelial mesenchymal transformation of high glucose induced-podocytes. Exp Ther Med 16, 1095-1102, 2018.

Chen J, Van Gulden S, McGuire TL, Fleming AC, Oka C, Kessler JA, Peng CY. BMP-responsive protease HtrA1 is differentially expressed in astrocytes and regulates astrocytic development and injury response. J Neurosci 38, 3840-3857, 2018.

Chevet E, Hetz C, Samali A. Endoplasmic reticulum stress-activated cell reprogramming in oncogenesis. Cancer Discov 5, 586-597, 2015.

Contois LW, Akalu A, Caron JM, Tweedie E, Cretu A, Henderson T, Liaw L, Friesel R, Vary C, Brooks PC. Inhibition of tumor-associated $\alpha v \beta 3$ integrin regulates the angiogenic switch by enhancing expression of IGFBP-4 leading to reduced melanoma growth and angiogenesis in vivo. Angiogenesis 18, 31-46, 2015.

D’Angelo V, Pecoraro G, Indolf P, Iannotta A, Donofrio V, Errico ME, Indolf C, Ramaglia M, Lombardi A, Di Martino M, Gigantino V, Baldi A, Caraglia M, De Luca A, Casale F. Expression and localization of serine protease Htral in neuroblastoma: correlation with cellular differentiation grade. J Neurooncol 117, 287-294, 2014.

Ding M, Bruick RK, Yu Y. Secreted IGFBP5 mediates mTORC1-dependent feedback inhibition of IGF-1 signalling. Nat Cell Biol 18, 319-327, 2016.

Doultsinos D, Avril T, Lhomond S, Dejeans N, Guedat P, Chevet E. Control of the Unfolded Protein Response in Health and Disease. SLAS Discov 22, 787-800, 2017.

Ellis BC, Graham LD, Molloy PL. CRNDE, a long non-coding RNA responsive to insulin/IGF signaling, regulates genes involved in central metabolism. Biochim Biophys Acta 1843, 372-386, 2014.

Ferris SP, Kodali VK, Kaufman RJ. Glycoprotein folding and quality-control mechanisms in protein-folding diseases. Dis Model Mech 7, 331-341, 2014.

Foulstone EJ, Zeng L, Perks CM, Holly JM. Insulin-like growth factor binding protein 2 (IGFBP-2) promotes growth and survival of breast epithelial cells: novel regulation of the estrogen receptor. Endocrinology 154, 17801793, 2013.

Gambaro K, Quinn MC, Caceres-Gorriti KY, Shapiro RS, Provencher D, Rahimi K, Mes-Masson AM, Tonin PN. Low levels of IGFBP7 expression in high-grade serous ovarian carcinoma is associated with patient outcome. BMC Cancer 15, 135, 2015. 
Ghoshal S, Stevens JR, Billon C, Girardet C, Sitaula S, Leon AS, Rao DC, Skinner JS, Rankinen T, Bouchard C, Nunez MV, Stanhope KL, Howatt DA, Daugherty A, Zhang J, Schuelke M, Weiss EP, Coffey AR, Bennett BJ, Sethupathy P, Burris TP, Havel PJ, Butler AA. Adropin: An endocrine link between the biological clock and cholesterol homeostasis. Mol Metab 8, 51-64, 2018.

Gokulakrishnan K, Velmurugan K, Ganesan S, Mohan V. Circulating levels of insulin-like growth factor binding protein-1 in relation to insulin resistance, type 2 diabetes mellitus, and metabolic syndrome (Chennai Urban Rural Epidemiology Study 118). Metab Clin Exp 61, 43-46, 2012.

Han J, Kaufman RJ. Measurement of the unfolded protein response to investigate its role in adipogenesis and obesity. Methods Enzymol 538, 135-150, 2014.

Han S, Li Z, Master LM, Master ZW, Wu A. Exogenous IGFBP-2 promotes proliferation, invasion, and chemoresistance to temozolomide in glioma cells via the integrin $\beta 1$-ERK pathway. Br J Cancer 111, 1400-1409, 2014.

Han J, Kaufman RJ. The role of ER stress in lipid metabolism and lipotoxicity. J Lipid Res 57, 1329-1338, 2016.

Hassler JR, Scheuner DL, Wang S, Han J, Kodali VK, Li P, Nguyen J, George JS, Davis C, Wu SP, Bai Y, Sartor M, Cavalcoli J, Malhi H, Baudouin G, Zhang Y, Yates III JR, Itkin-Ansari P, Volkmann N, Kaufman RJ. The IRE1a/XBP1s pathway is essential for the glucose response and protection of $\beta$ cells. PLoS Biol 13, e1002277, 2015.

Hermani A, Shukla A, Medunjanin S, Werner H, Mayer D. Insulin-like growth factor binding protein-4 and -5 modulate ligand-dependent estrogen receptor-alpha activation in breast cancer cells in an IGF-independent manner. Cell Signal 25, 1395-1402, 2013.

Holmes KM, Annala M, Chua CY, Dunlap SM, Liu Y, Hugen N, Moore LM, Cogdell D, Hu L, Nykter M, Hess K, Fuller GN, Zhang W. Insulin-like growth factor-binding protein 2-driven glioma progression is prevented by blocking a clinically significant integrin, integrin-linked kinase, and NF- $\kappa$ B network. Proc Natl Acad Sci U S A 109, 3475-3480, 2012.

Huang LE, Cohen AL, Colman H, Jensen RL, Fults DW, Couldwell WT. IGFBP2 expression predicts IDH-mutant glioma patient survival. Oncotarget 8, 191-202, 2017.

Hwang JR, Cho YJ, Lee Y, Park Y, Han HD, Ahn HJ, Lee JH, Lee JW. The C-terminus of IGFBP-5 suppresses tumor growth by inhibiting angiogenesis. Sci Rep 23, 39334, 2016.

Kim MS, Lee DY. Insulin-like growth factor (IGF)-I and IGF binding proteins axis in diabetes mellitus. Ann Pediatr Endocrinol Metab 20, 69-73, 2015.

Kuffer S, Gutting T, Belharazem D, Sauer C, Michel MS, Marx A, Trojan L, Strobel P. Insulin-like growth factor 2 expression in prostate cancer is regulated by promoter-specific methylation. Mol Oncol 12, 256-266, 2018.

Kuijjer ML, Peterse EF, van den Akker BE, Briaire-de Bruijn IH, Serra M, Meza-Zepeda LA, Myklebost O, Hassan $\mathrm{AB}$, Hogendoorn PC, Cleton-Jansen AM. IR/IGF1R signaling as potential target for treatment of high-grade osteosarcoma. BMC Cancer 13, 245, 2013.

Lee J, Ozcan U. Unfolded protein response signaling and metabolic diseases. J Biol Chem 289, 1203-1211, 2014.

Li X, Liu X, Zhang L, Li C, Zhang E, Ma W, Fan Q, Yu JJ. Insulin growth factor binding protein 2 mediates the progression of lymphangioleiomyomatosis. Oncotarget 8, 36628-36638, 2017.

Liu L, Yang Z, Zhang W, Yan B, Gu Q, Jiao J, Yue X. Decreased expression of IGFBP7 was a poor prognosis predictor for gastric cancer patients. Tumour Biol 35, 8875-8881, 2014.

Lopez MF, Zheng L, Miao J, Gali R, Gorski G, Hirschhorn JN. Disruption of the Igf2 gene alters hepatic lipid homeostasis and gene expression in the newborn mouse. Am J Physiol Endocrinol Metab 2018.

Mao Z, Zhang W. Role of mTOR in glucose and lipid metabolism. Int J Mol Sci 19, pii: E2043, 2018.

Maridas DE, DeMambro VE, Le PT, Mohan S, Rosen CJ. IGFBP4 is required for adipogenesis and influences the distribution of adipose depots. Endocrinology 158, 3488-3500, 2017.

Manie SN, Lebeau J, Chevet E. Cellular mechanisms of endoplasmic reticulum stress signaling in health and disease. 3. Orchestrating the unfolded protein response in oncogenesis: an update. Am J Physiol Cell Physiol 307, C901-C907, 2014.

Martin KA, Mani MV, Mani A. New targets to treat obesity and the metabolic syndrome. Eur J Pharmacol 763, 64-74, 2015.

Minchenko OH, Kubaichuk KI, Minchenko DO, Kovalevska OV, Kulinich AO, Lypova NM. Molecular mechanisms of ERN1-mediated angiogenesis. Int J Physiol Pathophysiol 5, 1-22, 2014.

Minchenko DO, Kharkova AP, Karbovskyi LL, Minchenko OH. Expression of insulin-like growth factor binding protein genes and its hypoxic regulation in U87 glioma cells depends on ERN1 mediated signaling pathway of endoplasmic reticulum stress. Endocr Regul 49, 73-83, $2015 \mathrm{a}$. 
Minchenko OH, Tsymbal DO, Minchenko DO, Moenner M, Kovalevska OV, Lypova NM: Inhibition of the endoribonuclease of ERN1 signaling enzyme affects the expression of proliferation-related genes in U87 glioma cells. Endoplasm Reticul Stress Dis 2, 18-29, 2015b.

Minchenko DO, Kharkova AP, Halkin OV, Karbovskyi LL, Minchenko OH. Effect of hypoxia on the expression of genes encoded insulin-like growth factors and some related proteins in U87 glioma cells without IRE1 function. Endocr Reg 50, 43-54, 2016.

Neuzillet Y, Chapeaublanc E, Krucker C, De Koning L, Lebret T, Radvanyi F, Bernard-Pierrot I. IGF1R activation and the in vitro antiproliferative efficacy of IGF1R inhibitor are inversely correlated with IGFBP5 expression in bladder cancer. BMC Cancer 17, 636, 2017.

Ord T, Ord D, Adler P, Vilo J, Ord T. TRIB3 enhances cell viability during glucose deprivation in HEK293-derived cells by upregulating IGFBP2, a novel nutrient deficiency survival factor. Biochim Biophys Acta 1853, 24922505, 2015.

Ozcan U, Cao Q, Yilmaz E, Lee AH, Iwakoshi NN, Ozdelen E, Tuncman G, Gorgun C, Glimcher LH, Hotamisligil GS. Endoplasmic reticulum stress links obesity, insulin action, and type 2 diabetes. Science 306, 457-461, 2004.

Peng T, Zhou L, Qi H, Wang G, Luan Y, Zuo L. MiR-592 functions as a tumor suppressor in glioma by targeting IGFBP2. Tumour Biol 39, $1010428317719273,2017$.

Poepsel S, Sprengel A, Sacca B, Kaschani F, Kaiser M, Gatsogiannis C, Raunser S, Clausen T, Ehrmann M. Determinants of amyloid fibril degradation by the PDZ protease HTRA1. Nat Chem Biol 11, 862-869, 2015.

Pollak M. The insulin and insulin-like growth factor receptor family in neoplasia: an update. Nat Rev Cancer 12, 159-169, 2012.

Praveen Kumar VR, Sehgal P, Thota B, Patil S, Santosh V, Kondaiah P. Insulin like growth factor binding protein 4 promotes GBM progression and regulates key factors involved in EMT and invasion. J Neurooncol 116, 455-464, 2014.

Ruderman NB, Carling D, Prentki M, Cacicedo JM. AMPK, insulin resistance, and the metabolic syndrome. J Clin Invest, 123, 2764-2772, 2013.

Sabin MA, Russo VC, Azar WJ, Yau SW, Kiess W, Werther GA: IGFBP-2 at the interface of growth and metabolism implications for childhood obesity. Pediatr Endocrinol Rev 8, 382-393, 2011.

Schillinger J, Severin K, Kaschani F, Kaiser M, Ehrmann M. HTRA1-Dependent Cell Cycle Proteomics. J Proteome Res 17, 2679-2694, 2018.

Shimba S, Ogawa T, Hitosugi S, Ichihashi Y, Nakadaira Y, Kobayashi M, Tezuka M, Kosuge Y, Ishige K, Ito Y, Komiyama K, Okamatsu-Ogura Y, Kimura K, Saito M. Deficient of a clock gene, brain and muscle Arnt-like protein-1 (BMAL1), induces dyslipidemia and ectopic fat formation. PLoS One 6, e25231, 2011.

Sun J, Lu Z, Deng Y, Wang W, He Q, Yan W, Wang A. Up-regulation of INSR/IGF1R by C-myc promotes TSCC tumorigenesis and metastasis through the NF-kappaB pathway. Biochim Biophys Acta 1864, 1873-1882, 2018.

Sunderic M, Dukanovic B, Malenkovic V, Nedic O. Molecular forms of the insulin-like growth factor-binding protein-2 in patients with colorectal cancer. Exp Mol Pathol 96, 48-53, 2014.

Tam J, Szanda G, Drori A, Liu Z, Cinar R, Kashiwaya Y, Reitman ML, Kunos G. Peripheral cannabinoid-1 receptor blockade restores hypothalamic leptin signaling. Mol Metab 6, 1113-1125, 2017.

Tang H, Leung L, Saturno G, Viros A, Smith D, Di Leva G, Morrison E, Niculescu-Duvaz D, Lopes F, Johnson L, Dhomen N, Springer C, Marais R. Lysyl oxidase drives tumour progression by trapping EGF receptors at the cell surface. Nat Commun 8, 14909, 2017.

Tiaden AN, Bahrenberg G, Mirsaidi A, Glanz S, Bluher M, Richards PJ. Novel function of serine protease HTRA1 in inhibiting adipogenic differentiation of human mesenchymal stem cells via MAP Kinase-mediated MMP upregulation. Stem Cells 34, 1601-1614, 2016.

Tsuchihara K, Ogura T, Fujioka R, Fujii S, Kuga W, Saito M, Ochiya T, Ochiai A, Esumi H. Susceptibility of Snarkdeficient mice to azoxymethaneinduced colorectal tumorigenesis and the formation of aberrant crypt foci. Cancer Sci 99, 677-682, 2008.

Wang S, Kaufman RJ. The impact of the unfolded protein response on human disease. J Cell Biol 197, 857-867, 2012.

Wang J, Ding N, Li Y, Cheng H, Wang D, Yang Q, Deng Y, Yang Y, Li Y, Ruan X, Xie F, Zhao H, Fang X. Insulin-like growth factor binding protein 5 (IGFBP5) functions as a tumor suppressor in human melanoma cells. Oncotarget 6, 20636-20649, 2015.

Wang M, Kaufman RJ. Protein misfolding in the endoplasmic reticulum as a conduit to human disease. Nature 529, 326-335, 2016. 
Yang B, Zhang L, Cao Y, Chen S, Cao J, Wu D, Chen J, Xiong H, Pan Z, Qiu F, Chen J, Ling X, Yan M, Huang S, Zhou S, Li T, Yang L, Huang Y, Lu J. Overexpression of lncRNA IGFBP4-1 reprograms energy metabolism to promote lung cancer progression. Mol Cancer 16, 154, 2017.

Yuan ZS, Cao Y, Li ZY. IGFBP2 induces SPRY1 expression via NF-kappaB signaling pathway in glioblastoma multiforme (GBM). Eur Rev Med Pharmacol Sci 21, 5072-5080, 2017.

Yuzefovych LV, Musiyenko SI, Wilson GL, Rachek LI. Mitochondrial DNA damage and dysfunction, and oxidative stress are associated with endoplasmic reticulum stress, protein degradation and apoptosis in high fat dietinduced insulin resistance mice. PLoS One 8, e54059, 2013.

Zurawa-Janicka D, Wenta T, Jarzab M, Skorko-Glonek J, Glaza P, Gieldon A, Ciarkowski J, Lipinska B. Structural insights into the activation mechanisms of human HtrA serine proteases. Arch Biochem Biophys 621, 6-23, 2017. 